\title{
PROGRAM PENYULUHAN PERSIAPAN MEMASUKI DUNIA KERJA BAGI SISWA SMKN 31 JAKARTA
}

\author{
Sari Zakiah Akmal, Rina Rahmatika, Novika Grasiaswaty
}

Fakultas Psikologi, Universitas YARSI

\begin{abstract}
Abstrak
Dengan kemampuan dan keterampilan yang dimiliki, seharusnya siswa SMK lebih mudah untuk diterima di dunia kerja. Pada kenyataannya, masih banyak lulusan SMK yang mengalami hambatan untuk memasuki dunia kerja. Hasil analisa kebutuhan dengan guru Bimbingan Konseling SMKN 31 ditemukan bahwa sebagian besar alumni SMKN 31 gagal untuk mendapatkan pekerjaan, terutama pada tahap psikotes dan wawancara. Kegagalan ini juga dialami oleh siswa-siswa yang memiliki prestasi akademis yang baik di sekolah. Berdasarkan hasil analisa kebutuhan terhadap siswa di SMKN 31, siswa juga menyatakan membutuhkan pelatihan untuk persiapan memasuki dunia kerja terutama persiapan untuk mengikuti psikotes dan wawancara. Oleh karena itu, diperlukan penyuluhan untuk mempersiapkan siswa SMKN 31 memasuki dunia kerja, terutama menghadapi psikotes dan wawancara. Kegiatan penyuluhan diikuti oleh 45 siswa SMK, dilaksanakan tanggal 23 Januri 2019 pukul 12.00 - 16.00. Untuk mengetahui efektivitas kegiatan, dilakukan evaluasi dengan membandingkan kemampuan siswa pada saat sebelum (pre test) dan setelah kegiatan (post test). Berdasarkan hasil evaluasi, diketahui bahwa kegiatan yang dilakukan dapat meningkatan pengetahuan siswa mengenai psikotes dan wawancara $(\mathrm{t}=$ 13.53, $\mathrm{p}<0.01$ ). Selain itu, kegiatan penyuluhan yang dilakukan juga mendapatkan penilaian positif dari peserta pada aspek kebermanfaatan kegiatan, sikap pemateri dan kejelasan materi yang disampaikan.
\end{abstract}

Kata kunci: siswa SMK, psikotes, wawancara, penyuluhan

\begin{abstract}
With the abilities and skills possessed, vocational schools students should be easier to accept in the workforce. In fact, there are still many vocational schools graduates who experience obstacles to entering the workforce. The results of the needs analysis with the Counselling Guidance Teacher at public vocational schools (SMKN) 31 were found that most of the alumni failed to get jobs, especially at the psychological test and interview stages. This failure is also experienced by students who have good academic achievements in school. Based on the results of needs analysis of students in Vocational High School 31, the students also stated that they needed training to prepare themselves to enter the workforce, especially preparation for selection process. Therefore, a training is needed to prepare vocational high school students to enter the workforce, especially facing psychological tests and interviews. This activities were attended by 45 vocational students, held on January 23, 2019 at 12.00-16.00. To find out the effectiveness of activities, an evaluation is carried out by comparing students' abilities before (pre test) and after the activity (post test). Based on the results of the evaluation, it is known that the activities carried out can improve students' knowledge about the psychological test and interview process $(t=13.53, p<0.01)$. In addition, the counseling also received positive evaluations from participants on the aspects of the usefulness of the activities, the attitude of the speaker and the clarity of the material presented.
\end{abstract}

Key words : Vocational school students, psychotest, interview, counseling

Correspondence author: Sari Zakiah, sari.zakiah@yarsi.ac.id, Jakarta, Indonesia,

This work is licensed under a CC-BY-NC 


\section{PENDAHULUAN}

Program pendidikan SMK memiliki tujuan yang berbeda dengan SMA. Siswa SMK tidak hanya dibekali dengan kemampuan akademis namun juga keterampilan spesifik yang sesuai dengan jurusan dan minat siswa. Lulusan SMK diharapkan lebih mudah mendapatkan pekerjaan dan membuka lapangan pekerjaan sendiri (Budianto, 2016). Akan tetapi, kondisi ini tidak sepenuhnya berlaku bagi seluruh lulusan SMK, salah satunya siswa lulusan dari SMKN 31 Jakarta.

SMKN 31 Jakarta merupakan salah satu sekolah SMK di wilayah Jakarta Pusat yang fokus mengembangkan keterampilan siswa di jurursan administrasi perkantoran, penjualan dan akuntansi. Ketiga jurusan tersebut memiliki kesempatan dan peluang kerja yang cukup besar mengingat pesatnya perkembangan ekonomi dan perusahaan di Jakarta. Berdasarkan hasil analisa kebutuhan dengan guru BK di SMKN 31 Jakarta yang dilakukan oleh guru Bimbingan Konseling terhadap 135 siswa diketahui bahwa masalah karier dan perencanaan masa depan merupakan masalah yang umum dihadapi siswa (36\%). Permasalahan mengenai karier dikelompokkan menjadi 14 tema utama, ditemukan bahwa siswa masih mengalami kendala dan minimnya informasi mengenai tatacara melamar pekerjaan $(78.1 \%)$, berbagai proses seleksi calon pegawai tertulis dan tidak tertulis $(92 \%)$. Kedua permasalahan tersebut mengindikasikan bahwa kurangnya kesiapan siswa dalam memasuki dunia kerja.

Kesiapan memasuki dunia kerja (work readiness) merupakan salah satu konstruk yang juga banyak dikembangkan dalam bidang ilmu psikologi. Kesiapan memasuki dunia kerja tidak hanya terbatas pada kesiapan untuk menghadapi proses seleksi. Kesiapan kerja didefinisikan sebagai sejauhmana lulusan dianggap memiliki sikap dan atribut yang dibutuhkan untuk siap dan sukses di dunia kerja (Caballero \& Walker, 2010). Kesiapan kerja ini menjadi hal yang penting karena dapat menjadi indikator potensi individu dalam performa kerja, kesuksesan dalam bidang pekerjaan dan potensi untuk promosi dan pengembangan karier (Caballero, Walker, \& Fuller-Tyszkiewicz, 2013).

Perkembangan ekonomi dan teknologi berdampak signifikan pada dunia kerja, termasuk pada efektivitas pelaksanaan rekruitmen dan seleksi pegawai baru. Kondisi tersebut menuntut perusahaan untuk mencari calon pekerja yang memiliki sikap kerja yang baik, mudah beradaptasi dan dapat melakukan berbagai hal sekaligus (Meyer, Allen \& Topolnytsky, 1998; Trank, Rynes \& Bretz Jr., 2002 dalam Caballero \& Walker, 2010). Secara umum, metode yang biasanya digunakan untuk seleksi calon pekerja adalah melalui form aplikasi, prestasi akademik, wawancara dan kemampuan kognitif yang diukur melalui tes (Caballero et al., 2013).

Pihak sekolah sudah mengupayakan beberapa cara untuk membantu mempersiapkan siswa seperti dengan mengadakan kegiatan magang/praktek kerja lapangan pada setting yang sesuai jurusan, mengadakan pelatihan untuk persiapan memasuki dunia kerja. Materi yang disampaikan pada saat pelatihan umumnya terkait dengan cara membuat lamaran dan tips menghadapi proses seleksi kerja (psikotes dan wawancara). Berdasarkan hasil evaluasi kegiatan, siswa merasakan manfaat dari kegiatan tersebut namun kurang memahami materi mengenai psikotes dan wawancara kerja. Oleh karena itu, guru Bimbingan Konseling selaku mitra kegiatan pengabdian masyarakat ini membutuhkan materi mengenai persiapan memasuki dunia kerja terutama mengenai persiapan menghadapi psikotes dan wawancara. 
Lulusan SMK sudah dibekali berbagai keterampilan praktis yang dibutuhkan untuk langsung terjun di dunia kerja. Akan tetapi, tingginya daya saing untuk dapat diterima di dunia kerja menjadi tantangan tersendiri bagi siswa SMK. Keterampilan yang dimiliki tidak menjamin keberhasilan mereka untuk dapat diterima bekerja di tempat yang sesuai dengan latar belakang pendidikannya. Masalah yang ditemui di lapangan adalah banyaknya siswa SMK yang gagal untuk memasuki dunia kerja karena tidak mendapatkan penilaian yang memuaskan pada saat seleksi kerja. Oleh karena itu, diperlukan sebuah kegiatan pelatihan untuk membantu siswa dalam mempersiapkan diri memasuki dunia kerja. Pada dasarnya, guru BK di SMKN 31 sudah berupaya untuk membantu menfasilitasi kebutuhan siswa akan keterampilan tersebut. Akan tetapi, guru BK masih memiliki keterbatasan dalam menjelaskan mengenai persiapan psikologis siswa dalam menghadapi seleksi kerja dan memasuki dunia kerja. Oleh karena itu, kami mengusulkan sebuah kegiatan pelatihan persiapan psikologis dalam menghadapi proses seleksi kerja dan menghadapi dunia kerja untuk siswa SMKN 31 Jakarta.

Beberapa tujuan kegiatan yang akan dilakukan, adalah untuk meningkatkan kesiapan kerja siswa, dengan:

1. Memberikan informasi kepada siswa $S M K N 31$ mengenai definisi kesiapan kerja dan pengukurannya.

2. Memberikan informasi kepada siswa SMKN 31 mengenai tips dan trik menghadapi psikotes dan wawancara.

Manfaat dari kegiatan ini adalah dapat meningkatkan kesiapan kerja siswa, dengan:

1. Meningkatkan pengetahuan siswa SMKN 31 mengenai kesiapan kerja dan cara pengukurannya.

2. Meningkatkan pengetahuan siswa SMKN 31 mengenai cara-cara menghadapi psikotes dan wawancara.

Kesiapan kerja (work readiness) merupakan konsep yang sekarang ini sudah cukup berkembang dan menjadi salah satu aspek yang dipertimbangkan dalam proses seleksi calon pegawai (Cabellero, Walker, \& Fuller-Tyszkiewicz, 2011). Kesiapan kerja diartikan sebagai sikap dan karakteristik yang dimiliki individu yang dibutuhkan oleh individu tersebut untuk dapat berhasil dan sukses di lingkungan pekerjaannya (Caballero \& Walker, 2010; Cabellero et al., 2011 \& Caballero et al., 2013). Kesiapan kerja individu merupakan indikator yang dapat memprediksi performa kerja kesuksesan dan promosi serta perkembangan karier (Caballero \& Walker, 2010; Cabellero et al., 2011 \& Caballero et al., 2013).

Cabellero dkk., (2011) melakukan studi kualitatif dan kuantitatif untuk mengetahui mengenai aspek-aspek kesiapan kerja dari perspektif calon pekerja dan pihak pengguna. Berdasarkan hasil penelitiannya, Cabellero dkk., (2011) mendapatkan empat aspek utama yang menggambarkan kesiapan kerja individu, yaitu:

1. Personal characteristics,

Karakteristik personal individu mengukur bagaimana daya lenting (resiliensi) dari individu, kemampuan untuk menyesuaikan diri di lingkugan kerja dan berbagai upaya pengembangan diri yang telah dilakukan. Aspek ini juga menggambarkan kemampuan personal, kemampuan untuk mengarahkan diri, pengenalan diri dan fleksibilitas. 
2. Organisational acumen,

Aspek ini mengukur motivasi untuk bekerja di organisasi atau institusi tertentu, kesadaran mengenai organisasi atau institusi di tempat kerja yang dituju, perkembangan personal dalam perusahaan atau keinginan untuk mempelajari hal baru dan sikap positif atau negatif terhadap pekerjaan. Aspek ini juga mengukur profesionalisme dan etika dalam bekerja, tanggung jawab sosial, dan pengetahuan umum.

3. Work competence,

Aspek kompetensi pekerjaan merupakan aspek yang menggambarkan kemampuan teknis individu (spesifik pada pekerjaan yang akan dituju), motivasi dalam menyelesaikan tugas dan kemampuan menyelesaikan masalah. Aspek ini juga menggambarkna kemampuan organisasional individu, berpikir kritis, kemampuan menyelesaikan masalah, dan kreativitas.

4. Social intelligence.

Aspek ini menggambarkan orientasi interpersonal, kemampuan bekerja dan kolaborasi dalam kelompok/tim, keterampilan sosial/interpersonal dan kemampuan komunikasi.

Aspek-aspek tersebut menggambarkan berbagai dimensi dari kesiapan kerja. Individu bisa saja unggul dalam salah satu aspek namun kurang menunjukkan kemampuan pada aspek lainnya. Oleh karena itu, kesiapan kerja biasanya dianggap sebagai konsep yang multidimensi (Cabellero dkk., 2011). Berbagai aspek kesiapan kerja tersebut akan diukur dengan menggunakan berbagai metode seperti: self report (dengan mengisi form aplikasi/lamaran kerja), tes kemampuan dan kepribadian serta wawancara (Cabellero dkk., 2011). Hasil pengukuran tersebut kemudian diintegrasikan sehingga dapat dibuat kesimpulan yang cukup komprehensif.

\section{Psikotes dan Wawancara Sebagai Salah Satu Pengukuran Kesiapan Kerja}

Faktor utama yang membedakan antara siswa yang baru lulus adalah kurangnya pengalaman kerja. Oleh karena itu, siswa yang baru lulus umumnya dipilih berdasarkan potensi umum yang dimiliki, dibandingkan dengan pengalaman atau peran khusus dalam dunia kerja. Kurangnya pengalaman kerja tersebut menyebabkan proses seleksi pegawai baru lulus tidaklah mudah dan membutuhkan pertimbangan yang lebih hatihati. Berbagai cara dilakukan untuk mendapatkan data terkait potensi kemampuan calon pekerja baru seperti: wawancara, tes pengetahuan-keterampilan-kepribadian dan kompetensi khusus terkait pekerjaan yang dituju (Keenan, 1995 dalam Caballero \& Walker, 2010).

Beberapa pendapat masih mendiskusikan apakah kesiapan kerja harus dimasukkan dalam suatu kriteria proses seleksi dalam mendapatkan pekerjaan (Caballero \& Walker, 2010). Dalam proses asesmen sendiri, penting untuk diketahui bahwa mendapatkan karyawan yang memiliki kemampuan tinggi dan pencapaian prestasi yang baik sebelumnya adalah hal yang dapat menunjang pengembangan perusahaan (Caballero \& Walker, 2010).

Para lulusan baru yang ingin mencari pekerjaan seringnya hanya fokus pada kemampuan umum yang diperlukan oleh perusahaan, tidak pada kemampuan spesifik yang sesuai dengan pekerjaan yang akan mereka lakukan (Carless, 2007). Oleh karena itu pelajar SMK yang akan masuk ke dunia kerja memerlukan pengetahuan spesifik terkait pekerjaan apa yang akan mereka lakukan. Hal ini diperlukan agar mereka dapat 
mempersiapkan diri untuk menghadapi proses rekrutmen yang nantinya menentukan apakah mereka akan mendapatkan pekerjaan tersebut atau tidak.

Untuk dapat mengukur potensi dan kesiapan kerja, umumnya proses seleksi meliputi penilaian verbal seperti wawancara. Proses wawancara ini biasanya menjadi hal yang cukup menantang bagi lulusan baru karena umumnya siswa lebih fokus pada penilaian secara tertulis. Oleh karena itu, siswa yang baru lulus tidak terbiasa dan tidak siap untuk mejelaskan secara lisan mengenai pengetahuan, keterampilan dan pengalamannya untuk menggambarkan potensi kemampuan yang dimiliki (Caballero \& Walker, 2010).

\section{METODE PELAKSANAAN}

Metode kegiatan yang digunakan adalah penyuluhan/ pelatihan singkat yang terdiri atas beberapa kegiatan. Kegiatan dilakukan dengan metode yang menarik seperti dengan menampilkan cuplikan video, studi kasus, sharing pengalaman, games dan sebagainya. Kegiatan pertama adalah pre-test untuk mengetahui level awal kemampuan siswa. Setelah itu, peserta akan diberikan penjelasan mengenai definisi kesiapan kerja dan berbagai cara pengukurannya dengan metode ceramah di depan kelas. Setelah mendapatkan gambaran umum mengenai kesiapan kerja, materi akan fokus pada persiapan menghadapi psikotes dan wawancara. Pada sesi ini, dijelaskan mengenai halhal yang diukur pada saat psikotes dan wawancara serta tips dan trik dalam menghadapi kedua proses tersebut. Pada penjelasan proses wawancara, dilakukan simulasi di depan kelas agar siswa lebih mendapatkan gambaran mengenai proses tersebut. Pada akhir sesi penyuluhan, diberikan post test untuk mengukur efektivitas dari kegiatan yang telah dilaksanakan.

Evaluasi dilakukan untuk melihat efektivitas kegiatan yang dilakukan, terutama untuk mengukur perubahan aspek kognitif (pengetahuan) peserta. Aspek yang diukur terkait dengan pengetahuan mengenai kesiapan kerja, psikotes dan wawancara. Evaluasi dilakukan sebanyak dua kali, yaitu pada saat sebelum kegiatan dan setelah kegiatan. Kegiatan dikatakan efektif apabila terdapat perbedaan signifikan antara skor pengetahuan sebelum dan setelah mengikuti kegiatan. Selain mengukur perbedaan pengetahuan peserta, pada akhir sesi juga dilakukan evaluasi pelaksanaan kegiatan yang bertujuan untuk mengetahui manfaat kegiatan yang dilakukan bagi siswa dan masukan/ saran terkait pelaksanaan kegiatan. Evaluasi ini hanya dilakukan satu kali pengambilan data, yaitu pada akhir kegiatan.

\section{HASIL DAN PEMBAHASAN}

Terdapat data dari 45 siswa yang dapat diolah atau lengkap baik pre maupun post tesnya. Hasil pre-test menunjukkan nilai rata-rata 2,53 $(\mathrm{SD}=1,63 ; \mathrm{df}=44)$ dan post-test sebesar 8,71 $(\mathrm{SD}=2,90 ; \mathrm{df}=44)$. Sedangkan perbedaan di antara keduanya adalah 6,18 $(\mathrm{SD}=3,06$; $\mathrm{df}=44)$. Uji t menunjukkan nilai $13,534(\mathrm{p}<0.001)$ yang mengindikasikan terdapat perbedaan pengetahuan peserta antara pre dan post test.

\section{Hasil Paired Sampe T-test}

\begin{tabular}{llll}
\hline Test & Mean & SD & N \\
\hline Pretest & 2,53 & 1,63 & 45 \\
Posttest & 8,71 & 2,90 & 45
\end{tabular}




\begin{tabular}{|c|c|c|c|}
\hline Nilai Beda & 6,18 & 3,06 & 45 \\
\hline & $\mathbf{T}=$ & $13,534 * *$ & \\
\hline
\end{tabular}

Berdasarkan hasil uji beda tersebut diketahui bahwa penyuluhan yang dilakukan efektif dalam meningkatkan pengetahuan siswa mengenai kesiapan kerja, psikotes dan wawancara. Penyuluhan bagi siswa SMK ini dilakukan berdasarkan hasil analisa kebutuhan, sesuai dengan penjelasan yang diberikan oleh guru Bimbingan Konseling. Oleh karena itu, tidaklah mengherankan jika rata-rata pengetahuan siswa pada saat pretest sanga rendah. Artinya, peserta masih memiliki pengetahuan yang sangat sedikit mengenai kesiapan kerja, psikotes dan wawancara. Pada saat pre-test, rata-rata skor pengetahuan peserta meningkat menjadi 8.71 (rata-rata dapat menjawab dengan benar lebih dari $80 \%$ persoalan). Hal ini diperkirakan dipengaruhi oleh metode penyampaian materi yang tidak hanya berupa ceramah, namun juga dilengkapi dengan demonstrasi dan role play. Semakin tinggi keterlibatan peserta dalam kegiatan pelatihan/penyuluhan maka semakin banyak materi yang diingat serta dipahami.

Selain melihat perbedaan nilai test sebelum dan sesudah, evaluasi juga dilakukan pada pelaksanaan kegiatan dengan menanyakan kepada peserta beberapa poin yang terkait dengan penyampaian materi. Dari skala 4, diketahui para siswa merasa jika kegiatan ini sangat bermanfaat (skor 3,78), dan materi yang diberikan telah jelas (skor 3,67). Sedangkan sikap pemateri telah dianggap baik (skor 3.52) dan metode kegiatan pun dianggap cukup tepat (skor 3.5). Selain secara kuantitatif, evaluasi juga dilaksanakan dengan kualitatf. Dari jawaban-jawaban para peserta, diketahui jika mereka merasa pemateri dianggap terlalu cepat dalam menyampaikan, serta usulan untuk melakukan permainan dan video yang menarik agar mereka lebih mudah memahami materi yang diberikan.

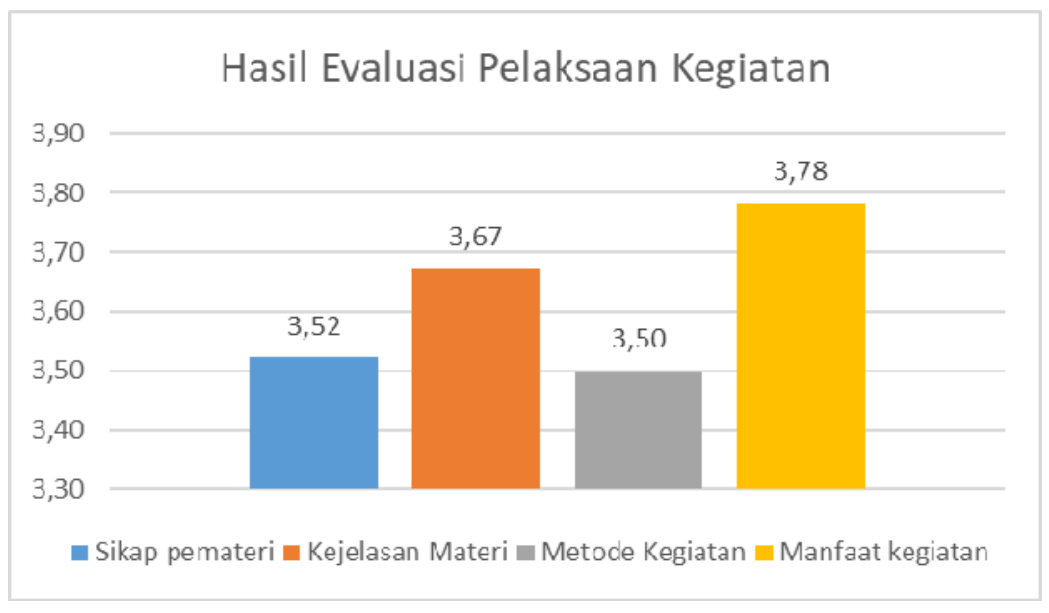

\section{SIMPULAN}

Dari pemaparan dan hasil pelaksanaan kegiatan pengabdian pada masyarakat tersebut, dapat dikatakan jika kegiatan penyuluhan pada siswa SMKN 31 tersebut cukup berhasil. Hal ini terlihat dari peningkatan skor tes sesudah mengikuti penyuluhan bila dibandingkan dengan skor tes mereka mengenai materi tersebut sebelumnya. Selain itu, evaluasi para peserta juga menunjukkan hasil yang positif mengingat semua aspek 
berada di atas 3.5 (dari 4.00) yang mengindikasikan jika peserta cukup puas dengan proses penyampaian materi yang dilakukan oleh penulis.

Adapun untuk ke depannya, akan lebih baik jika penyuluhan yang dilakukan mencakup aspek penting lain yang juga dibutuhkan oleh siswa SMK di dunia kerja, misalnya bagaimana berkomunikasi yang baik untuk semua jenjang serta bagaimana berempati terutama bagi mereka yang fokus pada pekerjaan-pekerjaan yang membutuhkan pertemuan dengan banyak orang.

\section{DAFTAR PUSTAKA}

Budianto, A. (2016). Profile Lulusan Sekolah Menengah Kejuruan di Kecamatan Wuryantoro Kabupaten Wonogiri Tahun Angkatan 2009 - 2014. Universitas Negeri Yogyakarta. Retrieved from http://eprints.uny.ac.id/41202/1/Arif Budianto_09101241014.pdf

Caballero, C. L. ., \& Walker, A. (2010). Work readiness in graduate recruitment and selection: A review of current assessment methods. Journal of Teaching and Learning for Graduate Employability, 1(1), 13-25. https://doi.org/10.1675/1524-4695(2008)31

Caballero, C. L. ., Walker, A., \& Fuller-Tyszkiewicz, M. (2013). The Work Readiness Scale (WRS): Developing a measure to assess work readiness in college graduate. Journal of Teaching and Learning for Graduate Employability, 2(2), $41-54$.

Cabellero, C., Walker, A., \& Fuller-Tyszkiewicz, M. (2011). The work readingess scale (WRS): Developing a measure to assess work readiness in college graduates. Journal of Teaching and Learning for Graduate Employability, 2(2), 41-54. https://doi.org/10.1111/1744-1609.12044

Carless, S. A. (2007). Graduate Recruitment and Selection in Australia. International Journal of Selection and Assessment, 15(2), 153-166. https://doi.org/10.1111/j.1468-2389.2007.00377.x 